Case Report

\title{
An Unusual Case of Systemic Lupus Erythematosus and Hemophagocytic Syndrome
}

\author{
Saika Sharmeen $^{1,2}$ and Nazia Hussain ${ }^{2,3}$ \\ ${ }^{1}$ Department of Medicine, St. Luke's-Roosevelt Hospital Center, New York, NY 10025, USA \\ ${ }^{2}$ Department of Medicine, Icahn School of Medicine at Mount Sinai, New York, NY 10025, USA \\ ${ }^{3}$ Division of Rheumatology, Department of Medicine, St. Luke's-Roosevelt Hospital Center, New York, NY 10025, USA
}

Correspondence should be addressed to Saika Sharmeen; ssharmeen@chpnet.org

Received 2 November 2015; Revised 5 January 2016; Accepted 13 January 2016

Academic Editor: Shoichiro Ikuyama

Copyright ( 92016 S. Sharmeen and N. Hussain. This is an open access article distributed under the Creative Commons Attribution License, which permits unrestricted use, distribution, and reproduction in any medium, provided the original work is properly cited.

\begin{abstract}
Hemophagocytic syndrome (HS) or hemophagocytic lymphohistiocytosis (HLH) is an immune mediated phenomenon that can occur in the setting of an autoimmune disease, chronic immunosuppression, malignancy, or infection. It has been more commonly described in the pediatric population and less commonly in adults. We describe a case of a 52-year-old male who presented with a rash. He simultaneously met the Systemic Lupus International Collaborating Clinics (SLICC) criteria for the diagnosis of systemic lupus erythematosus (SLE) and the diagnostic criteria of HS as described in the hemophagocytic lymphohistiocytosis (HLH) 2004 trial. The bone marrow on autopsy showed the presence of abundant hemosiderophages with focal hemophagocytosis. SLEassociated HS might be underdiagnosed due to the overlap in clinical findings. This case represents the importance of prompt diagnosis and treatment of such a potentially fatal clinical syndrome.
\end{abstract}

\section{Introduction}

Systemic lupus erythematosus (SLE) is one of the collagen vascular diseases which may induce hemophagocytic syndrome (HS). The etiology of HS is essentially unknown but is thought to result from uncontrolled $\mathrm{T}$ lymphocyte activation that leads to macrophage activation and an increment of some cytokines such as tumor necrosis factor- $\alpha$, interleukin1 (IL-1), IL-6, IL-18, and interferon- $\gamma$ [1]. Morphologically benign hemophagocytic histiocytes infiltrate the bone marrow and various organs, including the lymph nodes, liver, and spleen. Patients usually present with an acute febrile illness, which can sometimes become fulminant and lethal. Common manifestations include high fever, pancytopenia, hepatosplenomegaly, elevated liver enzymes, and high blood triglyceride and ferritin levels. Coagulopathy and central nervous system dysfunction often ensue, and less frequently the lungs and cardiac tissues are involved [2]. SLE in conjunction with HS is a rare presentation that has mainly been described in case reports and retrospective studies. It is a rare presentation in male patients and even more difficult to diagnose in a patient with history of alcohol abuse or cirrhosis where coagulopathy, elevated liver enzymes, and hepatosplenomegaly may also be expected. We demonstrate this difficulty in this case report of an African American male with history of alcohol abuse found to have SLE and HS. To our knowledge such a case in this demographic has never been reported.

\section{Case}

A 52-year-old African American male with past medical history only significant for alcohol abuse presented with four days of a pruritic rash. He was in his usual state of health until four days prior to admission when he noticed the rash. He could not remember if he first noticed it on his chest, abdomen, or legs. Over the next two days, it became more pruritic. He denied any shortness of breath or tongue swelling, as well as any constitutional symptoms including subjective fevers, night sweats, chills, or weight loss. He admitted to not seeing a primary care doctor in two years. He also denied any gait disturbance, gastrointestinal 
complaints, or urinary complaints but noted that his urine has been darker than usual. He endorsed daily alcohol use of about two to three beers daily but denied smoking or illicit drug use. He worked for the state and was working as of one day prior to admission. He admitted to recent travel in the northeast region. He denied taking any over-the-counter drugs or herbal medications.

Vitals at presentation were as follows: temp 98.9 degrees Fahrenheit, RR 16/min, HR 113-117/min, and BP $160 / 80 \mathrm{mmHg}$, saturating $100 \%$ on room air. On physical exam, skin exam was significant for nonblanching purpura on anterior calf bilaterally, pruritic nonblanching macules, and papules on chest, back, arms, abdomen, and petechial rash on his palms and soles bilaterally. The rash spared the groin area. Oral, ocular, and genital mucosa was clear. There was no skin tenderness. There was mild mucosal bleeding on lower lip. His eye exam showed scleral icterus. He also had lymphadenopathy on neck exam. He denied ever having a similar rash. On abdominal exam, he was found to have hepatosplenomegaly, with abdominal distention, and normoactive bowel sounds. There was no fluid shift. There was moderate pitting edema bilaterally but no clubbing or cyanosis. Neurologic exam was unremarkable at presentation.

Labs on presentation (Table 1) were significant for thrombocytopenia, hyponatremia, bilirubinemia, leukocytosis with left shift, normocytic anemia, and coagulopathy with elevated INR. His urine toxicology was negative. Urinalysis showed protein, moderate bilirubin, more than $182 \mathrm{RBC}, 13 \mathrm{WBC}$, and trace leukocyte esterase. Urine sediment showed many RBCs with less than $50 \%$ dysmorphic cells but no obvious casts.

EKG showed sinus tachycardia $105 \mathrm{bpm}$, with left axis deviation. Chest X-ray was unremarkable. Computed tomography (CT) of abdomen and pelvis with contrast showed multiple hypodense hypovascular lesions scattered throughout the liver causing surface contour deformity with numerous subcentimeter periportal, periaortic splenic, and periesophageal lymph nodes. Spleen was notable for linear as well as rounded ill-defined hypodensities suggestive of splenic infarcts, abscess, or malignancy. The initial differential was broad including infectious etiology causing sepsis, or malignancy. Given the appearance of the rash as well as history of travel to northeast, the patient was started on doxycycline for suspicion of Rocky Mountain Spotted Fever and supportive management for his remaining findings.

Over the next few days of his hospital course he developed acute mental status change with CT head without contrast showing nonspecific left parietal/temporal scalp soft tissue swelling and no other pathologies. On hospital day 2 he was transferred to the medicine intensive care unit (ICU) for being febrile with $T 101$ degrees Fahrenheit, renal failure, hepatic dysfunction, and worsening coagulopathy. CT chest without contrast showed focal areas of ground glass attenuation right greater than left. These findings may represent in this clinical setting pulmonary hemorrhage as well as bilateral pleural effusions. All blood cultures, urine cultures, and all infectious workup were negative (Table 3). In the ICU he had a cardiac arrest requiring cardiac resuscitation and
TABLE 1: Lab values on presentation.

\begin{tabular}{|c|c|c|}
\hline Variable & $\begin{array}{c}\text { Lab values on } \\
\text { admission }\end{array}$ & Reference range \\
\hline Sodium & 118 & $136-146 \mathrm{mmol} / \mathrm{L}$ \\
\hline Potassium & 4.9 & $3.5-5.1 \mathrm{mmol} / \mathrm{L}$ \\
\hline Chloride & 87 & $96-107 \mathrm{mmol} / \mathrm{L}$ \\
\hline Carbon dioxide & 23 & $22-30 \mathrm{mmol} / \mathrm{L}$ \\
\hline Blood urea nitrogen & 10 & $8-24 \mathrm{mmol} / \mathrm{dL}$ \\
\hline Creatinine & 0.89 & $0.66-1.25 \mathrm{mg} / \mathrm{dL}$ \\
\hline Glucose & 101 & $74-106 \mathrm{mg} / \mathrm{dL}$ \\
\hline eGFR & 90 & $>90$ \\
\hline Calcium & 7.7 & $8.4-10.3 \mathrm{mg} / \mathrm{dL}$ \\
\hline Corrected calcium ${ }^{*}$ & 8.7 & $8.5-10.5 \mathrm{mg} / \mathrm{dL}$ \\
\hline Protein, total & 8.7 & $6.3-8.2 \mathrm{~g} / \mathrm{dL}$ \\
\hline Albumin & 2.7 & $3.5-5 \mathrm{~g} / \mathrm{dL}$ \\
\hline Bilirubin, total & 4.8 & $0.2-1.3 \mathrm{mg} / \mathrm{dL}$ \\
\hline Bilirubin, direct & 3.5 & $0.0-0.4 \mathrm{mg} / \mathrm{dL}$ \\
\hline ALP & 187 & $38-126 \mathrm{U} / \mathrm{L}$ \\
\hline AST & 366 & $15-46 \mathrm{U} / \mathrm{L}$ \\
\hline ALT & 66 & $13-69 \mathrm{U} / \mathrm{L}$ \\
\hline WBC & 14.3 & $3.4-11 \mathrm{k} / \mu \mathrm{L}$ \\
\hline Hemoglobin & 8.3 & $13.0-17 \mathrm{~g} / \mathrm{dL}$ \\
\hline Hct & 27.7 & $38-51 \%$ \\
\hline Platelet & 72 & $150-450 \mathrm{k} / \mu \mathrm{L}$ \\
\hline $\mathrm{MCV}$ & 90.7 & 80-100 fL \\
\hline Band & 23 & \\
\hline Eosinophils (\%) & 2 & $0.0-0.6 \%$ \\
\hline Neutrophil (\%) & 70 & $40-74 \%$ \\
\hline Lymphocytes (\%) & 3 & $18-44 \%$ \\
\hline Monocytes (\%) & 2 & $4.7-12.0 \%$ \\
\hline Basophil (\%) & 0 & $0.1-1.4 \%$ \\
\hline Partial thromboplastin time & 51.3 & $22.5-35.5$ secs \\
\hline INR & 3 & $0.9-1.1$ \\
\hline PT & 30.8 & $11.8-14.3$ secs \\
\hline
\end{tabular}

${ }^{*}$ The normal albumin level defaults to $4 \mathrm{mg} / \mathrm{dL}$ standard units.

intubation, with return of spontaneous circulation. His hospital course was complicated with persistent fevers, gastrointestinal bleeding, acute kidney injury requiring hemodialysis, hypotension requiring pressor, and eventual acute respiratory distress syndrome with worsening liver failure. Later the lab results showed elevated ferritin level and $\mathrm{LDH}$ (Table 2). His rheumatologic workup (Table 3 ) revealed high titers of antidouble stranded DNA with low complement (C3/C4). Antinuclear antibody (ANA) was positive, antihistone antibodies (ab) negative, anti-Smith ab negative, antiribosomal $\mathrm{P}$ ab negative, antismooth muscle $\mathrm{ab}$ negative, and cardiolipin IgG/IgM moderately elevated. The patient was initially treated with broad spectrum antibiotics, despite negative cultures and infectious workup.

He received supportive management with packed red blood cell transfusion, fresh frozen plasma (FFP), and 
TABLE 2: Additional labs.

\begin{tabular}{lcc}
\hline Variable & Measurement & Reference range \\
\hline DAT broad spectrum & Negative & Negative \\
Coombs Ser (Direct Coombs) & & \\
GGT & 100 & $12-58 \mathrm{U} / \mathrm{L}$ \\
Tryptase & 4 & $2-10 \mathrm{ng} / \mathrm{mL}$ \\
Lipase & 22 & $23-300 \mathrm{U} / \mathrm{L}$ \\
Uric acid & 7.1 & $3.5-8.5 \mathrm{mg} / \mathrm{dL}$ \\
Lactic acid & 7.4 & $0.7-2.1 \mathrm{mmol} / \mathrm{L}$ \\
Ammonia & 42 & $9-30 \mu \mathrm{mol} / \mathrm{L}$ \\
Cryoglobulin & Negative & Negative \\
Creatine kinase & 920 & $55-170 \mathrm{U} / \mathrm{L}$ \\
CRP, high sensitivity & 10.4 & Null \\
Sedimentation rate & 100 & $0-13 \mathrm{~mm} / \mathrm{hr}$ \\
LDH & 2387 & $313-618 \mathrm{U} / \mathrm{L}$ \\
ADAMTS13 Activity & 84 & $68-163 \% \mathrm{activity}$ \\
G6PD & Adequate & Adequate \\
Haptoglobin, quant & 22 & $30-200 \mathrm{mg} / \mathrm{dL}$ \\
Ferritin & 700.7 & $22.0-322.0 \mathrm{ng} / \mathrm{mL}$ \\
Iron & 41 & $49-181 \mu \mathrm{g} / \mathrm{dL}$ \\
Iron binding capacity, total & 265 & $261-462 \mu \mathrm{g} / \mathrm{dL}$ \\
(TIBC) & 1 & $0.55-4.78 \mathrm{mIU} / \mathrm{mL}$ \\
Thyroid stim. hormone & 13.29 & $<.0-22.0 \mu \mathrm{g} / \mathrm{dL}$ \\
Cortisol AM & $66.5 \mu \mathrm{g} / \mathrm{mL}$ \\
Factor XI assay & 66 & $50-150 \%$ \\
Factor X assay & 64 & $50-150 \%$ \\
Factor II activity & 279 & $70-150 \%$ \\
Factor VIII assay & 16 & $50-150 \%$ \\
Factor VII assay & $49-150 \%$ \\
Factor V assay & & $50-150 \%$ \\
Fibrinogen & & $225-483 \mathrm{mg} / \mathrm{dL}$ \\
D-dimer & & $<3$ \\
\hline
\end{tabular}

platelets. He was also treated with pulse dose steroids for 3 days and then intravenous (IV) Medrol $40 \mathrm{mg}+$ $30 \mathrm{mg}$ daily. He also received plasmapheresis followed by IV Cytoxan with mild initial improvement, but unfortunately his condition deteriorated and the patient passed away. The autopsy revealed marked diffuse intra-alveolar hemorrhage, pulmonary edema, cirrhotic liver with cholestasis, acute tubular necrosis, chronic pancreatitis, infarcted spleen, and evidence of esophageal varices in a patient with known chronic alcoholism. The bone marrow showed the presence of abundant hemosiderophages with focal hemophagocytosis, which added to the presence of fever, splenomegaly, skin rash, cytopenia, and increased ferritin which met the criteria for hemophagocytic lymphohistiocytosis.

\section{Discussion}

Our patient met 4 out of 17 (including at least one clinical criterion and one immunologic criterion) of the Systemic Lupus International Collaborating Clinics (SLICC) criteria
TABLE 3: Autoimmune and infectious workup.

\begin{tabular}{|c|c|c|}
\hline Variable & Measurement & Reference range \\
\hline ANA & Positive & Negative \\
\hline ANA, quantitative & $1: 160$ & Negative \\
\hline ANA, pattern & Speckled & Negative \\
\hline ds DNA ab IgG Titer & 300 or greater & 0-29 IU/ML \\
\hline C3 & 23 & $90-180 \mathrm{mg} / \mathrm{dL}$ \\
\hline $\mathrm{C} 4$ & 3 & $10-40 \mathrm{mg} / \mathrm{dL}$ \\
\hline Anti-Smith (Sm) interp. & Negative & Negative \\
\hline $\begin{array}{l}\text { SM-RNP antibodies } \\
\text { interp. }\end{array}$ & Negative & Negative \\
\hline SM-RNP ab interp. & Negative & Negative \\
\hline Smith (ENA) ab, IgG & 0.8 & $<16.00 \mathrm{EU} / \mathrm{mL}$ \\
\hline SSA (Sjogren ab) & 0.7 & $<16.00 \mathrm{EU} / \mathrm{mL}$ \\
\hline SSB (Sjogren ab) & 1 & $<16.00 \mathrm{EU} / \mathrm{mL}$ \\
\hline Ribosomal P ab & $<1.0$ & Negative \\
\hline Smooth muscle ab & Negative & Negative \\
\hline LKM 1 ab IgG & $<20.0 \mathrm{U}$ & Negative \\
\hline GBM ab IgG & $<1.0$ & $\begin{array}{c}<1.0 \text { AI no antibody } \\
\text { detected }\end{array}$ \\
\hline Histone ab & 1.2 & $<1.0 \mathrm{U}$ negative \\
\hline Cardiolipin ab IgM & 24 & $\begin{array}{l}\text { Low to medium } \\
\text { positive }\end{array}$ \\
\hline Cardiolipin ab IgG & 20 & Indeterminate \\
\hline$\beta 2$-Glycoprotein I IgM & Negative & Negative \\
\hline$\beta 2$-Glycoprotein I IgA & 9 & Negative \\
\hline \multicolumn{3}{|l|}{ ANCA vasculitides } \\
\hline Proteinase $3 \mathrm{ab}$ & $<1.0$ & $<1.0$ \\
\hline Myeloperoxidase ab & $<1.0$ & $<1.0$ \\
\hline Hep A ab, IgM & Nonreactive & Nonreactive \\
\hline Hep A ab, total & Nonreactive & Nonreactive \\
\hline Hep B sAg & Negative & Negative \\
\hline Hep B Core ab, total & Reactive & Nonreactive \\
\hline Hep BS ab & Reactive & Nonreactive \\
\hline Hep C ab & Negative & Negative \\
\hline HIV $1 / 2$ ab screen, rapid & Nonreactive & Nonreactive \\
\hline Cytomegalovirus, IgM & 0.7 & $<0.9$ \\
\hline Cytomegalovirus, Igg & Negative & Negative \\
\hline $\begin{array}{l}\text { EBV, DNA, QN, and } \\
\text { PR-PCR }\end{array}$ & $<200$ COPIES/ML & Negative \\
\hline Syphilis Screen Titer & Nonreactive & Nonreactive \\
\hline Lyme Disease ab Screen & 0.58 & $<0.91$ \\
\hline RMSF IgM and IgG & Not detected & Not detected \\
\hline B. Quintana IgM Scr & Negative & Negative \\
\hline B. Quintana IgG Scr & Negative & Negative \\
\hline B. Henselae ab IgG & Negative & Negative \\
\hline Brucella IgG & 0.16 & $\begin{array}{c}<0.80 \text { antibody not } \\
\text { detected }\end{array}$ \\
\hline Brucella IgM & 0.07 & $\begin{array}{c}<0.80 \text { antibody not } \\
\text { detected }\end{array}$ \\
\hline
\end{tabular}


TABLe 3: Continued.

\begin{tabular}{lcc}
\hline Variable & Measurement & Reference range \\
\hline $\begin{array}{l}\text { AFB culture } \\
\text { Fungal culture }\end{array}$ & Negative & Negative \\
Viral culture & $\begin{array}{r}\text { Nogative } \\
\text { after } 4 \text { days }\end{array}$ & Negative \\
Gram stain & $\begin{array}{r}\text { Few } 2+\text { PMN no } \\
\text { organisms }\end{array}$ & Negative \\
Bacterial culture & No growth & Negative \\
\hline
\end{tabular}

for the diagnosis of SLE [3]. Our patient's findings included thrombocytopenia and hemolytic anemia as two clinical criteria and positive anti-dsDNA ab and low complement (C3/C4) as immunologic criteria. Our patient also met the diagnostic criteria for HS as described in the hemophagocytic lymphohistiocytosis (HLH) 2004 trial.

He had a fever of $38.5^{\circ} \mathrm{C}$ for 7 days or more, splenomegaly, hemoglobin of $9 \mathrm{~g} / \mathrm{dL}$ or less, platelets less than 100 , hyperferritinemia, and hemophagocytosis in bone marrow [4]. Lambotte et al. described 8 cases where SLE was diagnosed simultaneously with HS pancytopenia with high ferritin level, uncommon in SLE, which is highly suggestive of HS [5]. Parodi et al. proposed preliminary diagnostic criteria for macrophage activation syndrome as a complication of juvenile SLE. The diagnostic criteria have a sensitivity and specificity of $92.1 \%$ and $90.9 \%$, respectively, and an OR of $116.7 \%$ with a confidence interval between 21.9 and 621.6 at $95 \%$ confidence [6]. According to the diagnostic criteria proposed by Parodi et al., our patient met all clinical criteria including fever $\left(>38^{\circ} \mathrm{C}\right)$, hepatomegaly $(\geq 3 \mathrm{~cm}$ below the rib margin), splenomegaly ( $\geq 3 \mathrm{~cm}$ below the rib margin), hemorrhagic manifestations (purpura, easy bruising, or bleeding gums), and dysfunction of the central nervous system (irritability, disorientation, lethargy, headache, convulsions, or coma). He also met most of the laboratory criteria including cytopenia in 2 or more cell lines [4 leukocytes $\times$ $109 / \mathrm{L}$, hemoglobin $90 \mathrm{~g} / \mathrm{L}$, or platelets $150 \times 109$, increased aspartate aminotransferase ( $>40$ units/L), increased lactate dehydrogenase ( $>567$ units/L), hypofibrinogenemia (fibrinogen $<1.5 \mathrm{~g} / \mathrm{L}$ ), and hyperferritinemia (ferritin $>500 \mu \mathrm{g} / \mathrm{L}$ )]. The histopathologic criteria were also met by evidence of hemophagocytic macrophages in bone marrow. For diagnosis, the simultaneous presence of at least one clinical criterion and at least 2 laboratory criteria is required.

HIV, cytomegalovirus, and Epstein-Barr virus are among the reported viral causes of HS [7,8]. Although infections are a possible trigger for HS, our patient had an extensive infectious workup which was all shown to be negative (Table 2). Unfortunately, liver biopsy could not be done due to the coagulopathy. In addition, his disease continued to progress despite broad spectrum antibiotics and supportive treatment. His mild clinical improvement after pulse steroids and IV Cytoxan was in favor of the trigger for HS being autoimmune in etiology. This patient also received plasmapheresis without improvement. The presence of chronic alcoholism causing cirrhosis further complicated the diagnosis.
The current literature suggests that the goal of therapy for patients with HLH is to suppress life-threatening inflammation by destroying immune cells. The first treatment protocol for HLH (HLH-94) consists of induction therapy with weekly treatments of dexamethasone and etoposide (VP-16), followed by cyclosporine. Intrathecal methotrexate is given to those with central nervous system disease. After induction, patients who are recovering are weaned off therapy, while those who are not improving are continued on therapy as a bridge to allogeneic hematopoietic cell transplantation [9]. The newer HLH protocol initiated in 2004 (HLH-2004) differs from HLH-94 by earlier use of cyclosporine during the induction phase of treatment and adds hydrocortisone to intrathecal methotrexate. Treatment of secondary HLH is directed at control of the underlying condition. If unsuccessful, cytotoxic agents such as those in HLH-2004, steroids, intravenous $\gamma$-globulin, or targeted immune therapy have been used [10]. Steroids and other immunosuppressants including Rituximab have also been reported in successfully treating HS in the setting of SLE $[11,12]$. Wong et al. reported an incidence of SLE-associated HS of 6 cases during a 3.5year period among 250 SLE patients. They alluded to the fact that SLE-associated HS might be underdiagnosed due to the overlap in clinical findings [13]. Moreover, this case was even more difficult to diagnose because many of the findings that would be expected in a patient with alcoholic cirrhosis were also present in this patient.

\section{Conclusion}

In conclusion, a prompt diagnosis is essential for treating HS in the setting of SLE. Clinicians should raise a high index of suspicion in such a case.

\section{Conflict of Interests}

The authors declare that there is no conflict of interests regarding the publication of this paper.

\section{References}

[1] J. I. Henter, A. C. Horne, M. Arico, M. Egeler, A. H. Filipovich, and S. Imashuku, Histiocyte Society Review HLH-2004: Diagnostic and Therapeutic Guidelines for Hemophagocytic Lymphohistiocytosis, Wiley-Liss, Stockholm, Sweden, 2006.

[2] S. Fukaya, S. Yasuda, T. Hashimoto et al., "Clinical features of haemophagocytic syndrome in patients with systemic autoimmune diseases: analysis of 30 cases," Rheumatology, vol. 47, no. 11, pp. 1686-1691, 2008.

[3] M. Petri, A. M. Orbai, G. S. Alarcón et al., "Derivation and validation of the Systemic Lupus International Collaborating Clinics classification criteria for systemic lupus erythematosus," Arthritis \& Rheumatism, vol. 64, no. 8, pp. 2677-2686, 2012.

[4] M. B. Jordan, C. E. Allen, S. Weitzman, A. H. Filipovich, and K. L. McClain, "How I treat hemophagocytic lymphohistiocytosis," Blood, vol. 118, no. 15, pp. 4041-4052, 2011.

[5] O. Lambotte, M. Khellaf, H. Harmouche et al., "Characteristics and long-term outcome of 15 episodes of systemic 
lupus erythematosus-associated hemophagocytic syndrome," Medicine, vol. 85, no. 3, pp. 169-182, 2006.

[6] A. Parodi, S. Davì, A. B. Pringe et al., "Macrophage activation syndrome in juvenile systemic lupus erythematosus: a multinational multicenter study of thirty-eight patients," Arthritis and Rheumatism, vol. 60, no. 11, pp. 3388-3399, 2009.

[7] K. McClain, R. Gehrz, H. Grierson, D. Purtilo, and A. Filipovich, "Virus-associated histiocytic proliferations in children. Frequent association with Epstein-Barr virus and congenital or acquired immunodeficiencies," The American Journal of Pediatric Hematology/Oncology, vol. 10, no. 3, pp. 196-205, 1988.

[8] T.-L. Chen, W.-W. Wong, and T.-J. Chiou, "Hemophagocytic syndrome: an unusual manifestation of acute human immunodeficiency virus infection," International Journal of Hematology, vol. 78, no. 5, pp. 450-452, 2003.

[9] J.-I. Henter, A. Samuelsson-Horne, M. Aricò et al., "Treatment of hemophagocytic lymphohistiocytosis with HLH-94 immunochemotherapy and bone marrow transplantation," Blood, vol. 100, no. 7, pp. 2367-2373, 2002.

[10] M. P. Keith, C. Pitchford, and W. B. Bernstein, "Treatment of hemophagocytic lymphohistiocytosis with alemtuzumab in systemic lupus erythematosus," Journal of Clinical Rheumatology, vol. 18, no. 3, pp. 134-137, 2012.

[11] M. W. So, B. S. Koo, Y. J. Kim, Y.-G. Kim, C.-K. Lee, and B. Yoo, "Successful rituximab treatment of refractory hemophagocytic lymphohistiocytosis and autoimmune hemolytic anemia associated with systemic lupus erythematosus," Modern Rheumatology, vol. 24, no. 5, pp. 855-857, 2014.

[12] S. Kumakura and Y. Murakawa, "Clinical characteristics and treatment outcomes of autoimmune-associated hemophagocytic syndrome in adults," Arthritis \& Rheumatology, vol. 66, no. 8, pp. 2297-2307, 2014.

[13] K.-F. Wong, P.-K. Hui, J. K. C. Chan, Y.-W. Chan, and S.-Y. Ha, "The acute lupus hemophagocytic syndrome," Annals of Internal Medicine, vol. 114, no. 5, pp. 387-390, 1991. 


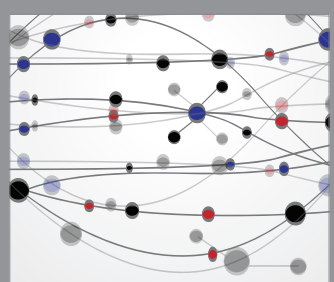

The Scientific World Journal
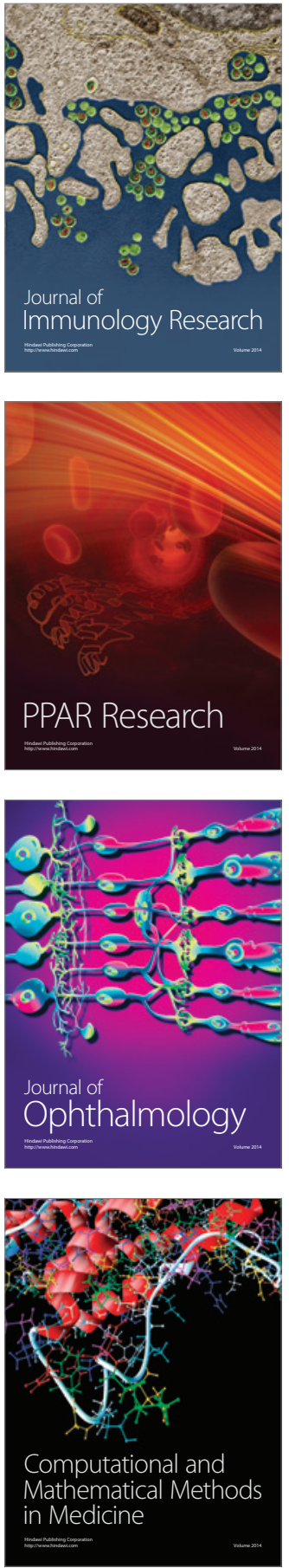

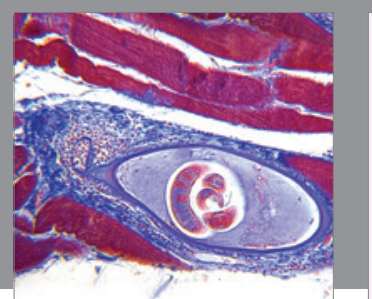

Gastroenterology Research and Practice

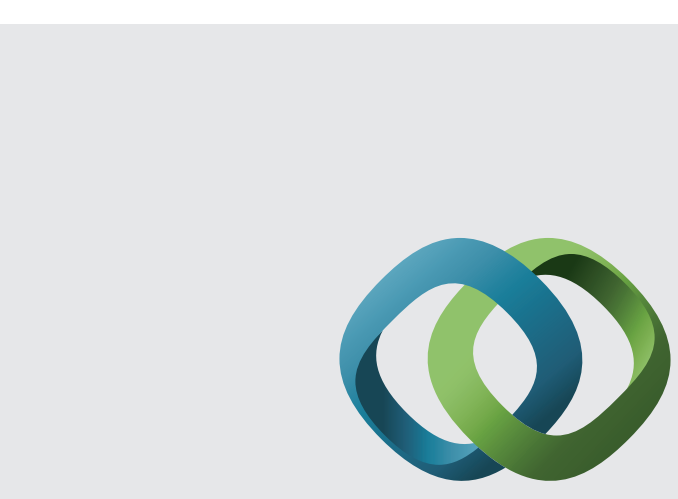

\section{Hindawi}

Submit your manuscripts at

http://www.hindawi.com
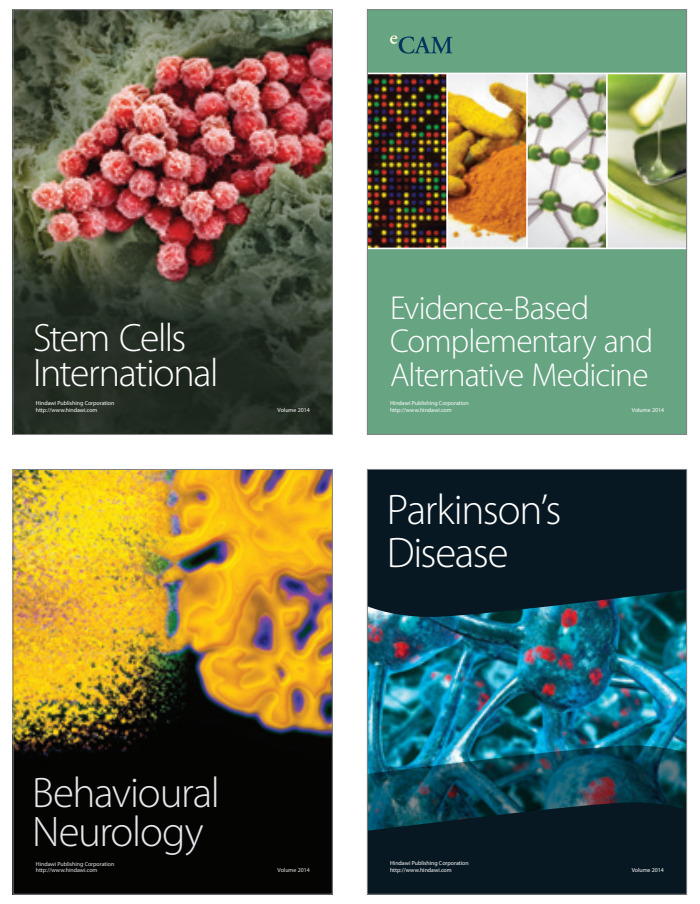
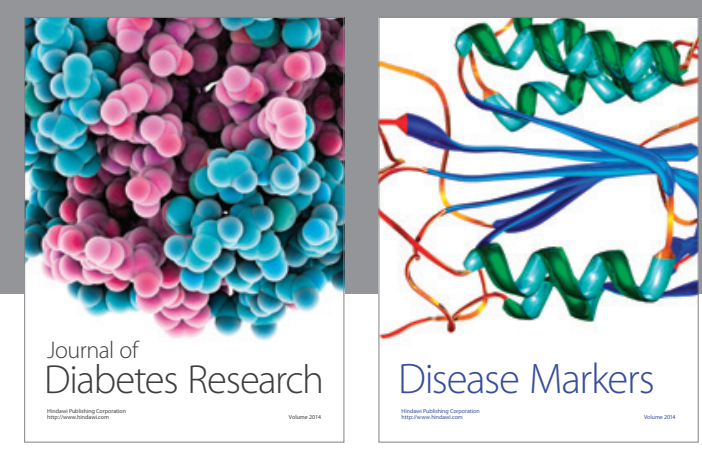

Disease Markers
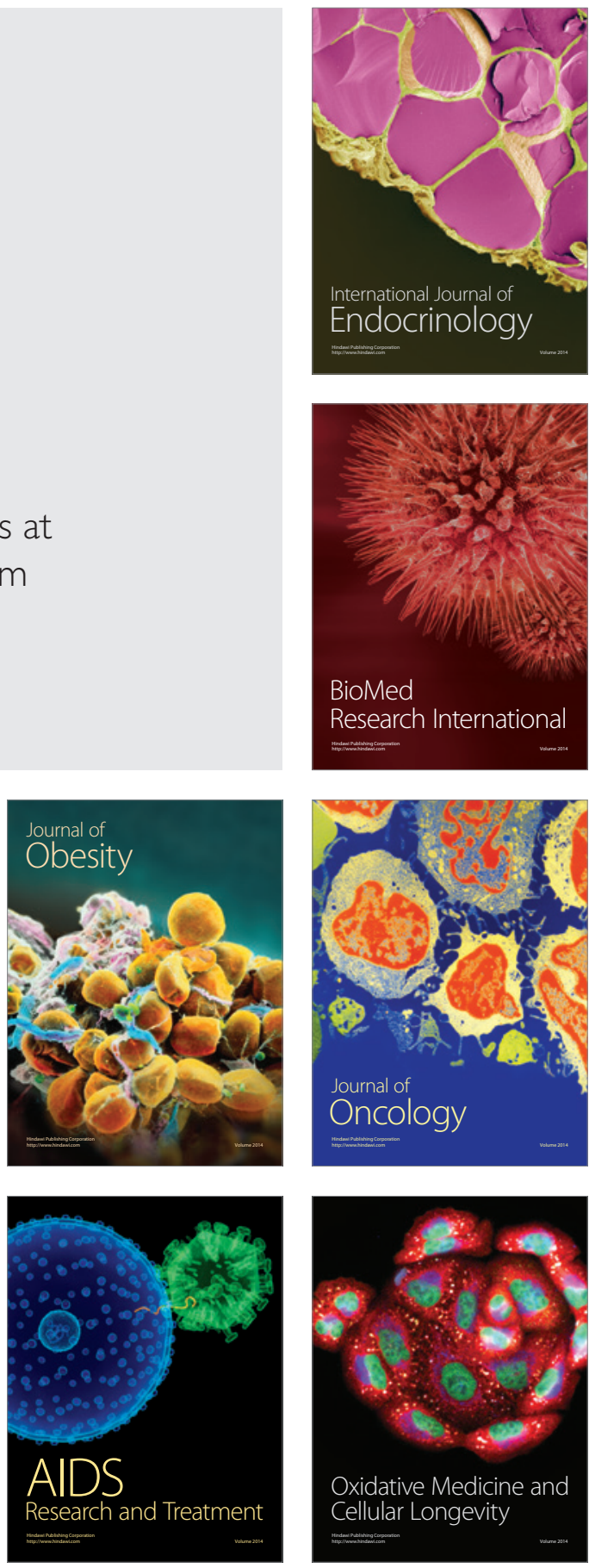